\title{
Identifying Early Determinants for Chronic Kidney Disease of Uncertain Aetiology (CKDu) Amongst Agricultural Communities in Sri Lanka
}

\section{Jayasekara $\mathrm{K}^{1 *}$, Gunaratne $\mathrm{G}^{2}$, Nisansala $\mathrm{T}^{3}$, Kulasooriya $\mathrm{P}^{3}$ and Gunawickrama ${ }^{4}$}

${ }^{1}$ Department of Medical Laboratory Sciences, Sir John Kotelawala Defence University, Sri Lanka

${ }^{2}$ Faculty of Management and Finance, University of Colombo, Sri Lanka ${ }^{3}$ University Hospital, Sir John Kotelawala Defence University, Sri Lanka ${ }^{4}$ KDU CARE, Sir John Kotelawala Defence University, Sri Lanka

\section{Research Article}

Volume 5 Issue 4

Received Date: November 16, 2021

Published Date: December 28, 2021

DOI: $10.23880 /$ eij-16000215

*Corresponding author: Kithsiri Jayasekara, Department of Medical Laboratory Sciences, Sir John Kotelawala Defence University, Sri Lanka, Tel: +94776971907; Email: kbjayasekara@gmail.com

\section{Abstract}

Background: In the North Central Region (NCR) of Sri Lanka, health experts have noted a significant prevalence of CKD due to uncertain aetiology ( $\mathrm{CKDu}$ ). The disease is more prevalence among farming communities.

Objectives: This study aims to use case-control studies to determine the agricultural and sociological risk variables associated with CKDu in farming communities.

Methods: Information regarding exposure to risk factors, employing labour for agricultural activities and pesticide protection status were obtained from 274 recently diagnosed, confirmed CKDu patients. Eventually formed age and sex-matched healthy individuals (274) were selected as controls. Information regarding drinking water sources, smoking, alcohol use, family history of $\mathrm{CKDu}$, snake envenomation, and malaria history were also gathered from both groups.

Results: The conditional logistic regression model was used to compare the relative risk of each component. Engagement in agricultural activities involving more than 2 hectares (OR: 3.415), poor agrochemical protection (OR: 1.966), and cultivating fields without employing labour (OR: 4.383) were found as major risk factors for CKDu. Smoking(OR: 2.951) and a family medical history of $\mathrm{CKDu}(\mathrm{OR}: 2.809)$ were also found as significant lifestyle-related risk factors in farming communities, as were consuming drinking water from shallow wells(OR: 2.050) and snake envenomation(OR: 1.602).

Significance: Severe agricultural activities and poor pesticide protection status point to the need for farmers to be educated on safe agriculture and agrochemical use.

Keywords: Chronic Kidney Disease; Agricultural Activities; Ckdu; Smoking; Agrochemicals; Agricultural Risk Factors

Abbreviations: NCR: North Central Region; CKD: Chronic Kidney Disease; ESRD; End-Stage Renal Disease; CKDu:
Chronic Kidney Disease Of Uncertain Aetiology; AKI: Acute Kidney Injury. 


\section{Epidemiology International Journal}

\section{Introduction}

Chronic kidney disease (CKD) is fast becoming a global epidemic [1]. According to data from the United States, for a single patient diagnosed with end-stage renal disease (ESRD), there are over 200 with diagnosed CKD and almost 5,000 patients with incipient CKD. Unfortunately, most developing countries do not have access to such information. Chronic kidney disease (CKD) is a major health concern in Sri Lanka, as it is in other countries, with diabetes and hypertension being the primary contributors to the disease burden. Diabetes (44\%) and hypertension $(17 \%)$ were the most prevalent underlying causes of CKD, according to crosssectional research conducted in 2011 at the National Hospital in Colombo, where results showed that $54 \%$ of CKD patients were at stage $\mathrm{V}$ of the disease. The most prevalent cause in patients younger than 40 years old with no indications of diabetes or hypertension was glomerulonephritis (42.6 percent) [2].

Two decades ago, medical professionals in Sri Lanka discovered a disconcertingly high incidence of a particular type of chronic kidney disease of uncertain aetiology (CKDu) in certain parts of the island's North Central, Uva, and North-Western provinces, which are considered a unique geographical terrain and are referred to as the North Central Region (NCR) [3]. Over the last 15-20 years, the condition has become much more prevalent. Although the exact number of persons affected is unclear, it is thought that roughly 100,000 people are now receiving treatment for this condition. Chronic kidney disease (CKD) is caused by diabetes, hypertension, and infection in other regions of the country [4]. However, none of the recognized causes of CKD was found in NCR. Tubulointerstitial nephritis, which is often classified as chronic kidney disease due to toxic aetiology, was found on histopathology of the damaged kidneys [5]. According to the research, undiscovered environmental toxins or occupational exposure induce CKD in men from low socioeconomic backgrounds who are employed in rice farming, suggesting the plausibility of agrochemical exposure as a cause of $\mathrm{CKDu}[3]$.

The NCR, which has a high prevalence of chronic renal disease, is characterized by a complex network of man-made reservoirs and canals that have provided water for rice farming, as well as for human and livestock consumption, for over 800 years. The average annual rainfall is less than 1250 $\mathrm{mm}$, and the average temperature is $34+2.5$ (SD) degrees Celsius. Agriculture is the most significant sector of the economy in both the NCR and the entire nation, accounting for $30 \%$ (2.26 million hectares) of the total land area, with 80 per cent of it being in the dry zones [6]. Rice is the staple food in Sri Lanka, and it is grown on a local scale by farmers in rural areas, mostly in the NCR, where rice cultivation employs $90 \%$ of the population. Individual holdings are no larger than 3 hectares, and rice cultivation is done on a modest scale by family members. Rice cultivation is highly reliant on rainfall and farmers engage in labour-intensive agricultural activities with little mechanization. In their open agricultural areas, many farmers conduct all farming chores manually, including land preparation, planting, harvesting, and tilling. The area used to cultivate rice expanded sixfold between 1960 and 2000, reaching 546,249 hectares, yet the majority of farmers still employ conventional methods, though with substantial use of agrochemicals.

Certain parts of the NCR have a higher prevalence of CKDu. High levels of fluoride in groundwater [5], the bleaching of heavy metals like cadmium and arsenic from synthetic fertilizers into water sources $[7,8]$, and the use of aluminium containers to hold drinking water have all been suggested as risk factors for CKDu [9]. These findings clearly show that the illness is mostly impacting the male agricultural population in specific regions of Sri Lanka's NCR. However, the aetiology of the disease in Sri Lanka's NCR region is yet uncertain. According to the studies conducted on chronic kidney disease, environmental toxins may have a role in the aetiology of CKDu. As a result, the goal of this study is to use case-control research to assess agricultural and lifestyle-related risk factors of CKDu amongst agricultural communities in the NCR, Sri Lanka.

\section{Methods}

The names and addresses of 726 confirmed interstitial nephritis patients with unknown aetiology (CKDu) were obtained from renal clinics in three high-prevalence locations (Madawachchiya, Padaviya, and Kebithigollawa). Each patient was assigned a registration number based on the chronology in which they arrived at the renal clinics. The study included every third subject on the list $(n=274)$. One hundred and eighty-four (184) males and 90 females in the case group (Mean age 56.4+10.6 years) and eventually formed age and sex-matched healthy individuals (274) were selected as controls (Mean age $56.1+12.5$ years) from the adjacent house of each CKDu patient. The Provincial Director, Provincial Director's office (Health), Anuradhapura, Sri Lanka, provided ethical approval and permission for the study. Oral informed consent was obtained from all patients and control. Age and the gender-matched case-control study were accomplished on the basis of potential confounding variables.

The diagnosis of CKDu is attributed to the absence of hypertension, diabetes mellitus, UTIs or other renal diseases in the past, decreased eGFR (MDRD formula), proteinuria on 2 occasions, the incidence of radiological changes like a normal kidney in early stages, and reduction in kidney size, 


\section{Epidemiology International Journal}

decreased eGFR (MDRD formula) and increased cortical echogenicity. Interstitial inflammation and fibrosis were the first pathological manifestations, followed by tubular atrophy and glomerulosclerosis in later stages [10]. Healthy individuals (absence of any chronic disorder) were selected after two consecutive early morning urine samples showed the absence of proteinuria by urine protein turbidimetric assay (urine protein $<15 \mathrm{mg} / \mathrm{dl}$, detection limit 4-200mg/dl, sensitivity $4 \mathrm{mg} / \mathrm{dl})$.

Farmers typically wear long-sleeved shirts and long pants (basic wear) as a safety precaution when employing agrochemicals, as per local agricultural practices. Farmers who were not involved in agricultural activities or who wore waterproof rubber gloves and masks (two-strap respirators) and covered shoes in addition to the above protective measures were deemed to have a high protective status, while those who only wore basic protective measures were deemed to have a low protective status. The different types of agrochemicals used on farmland were also noted.

When farmers cultivated two or more hectares of the farming area it was considered to be 'high' activity, and when they cultivated less than two hectares and/or not engaging in agricultural activities, it was termed as 'low' activity. When it comes to agricultural operations in Sri Lanka, there are two types of farming operations. The first category is made up of farmers who perform their own farming on their own property and are classified as low level of labour hiring. The second set of farmers relied on hired labour to do agricultural tasks, rather than participating in physical labour themselves. This group was labeled as having a 'high labour hiring. Aside from agricultural variables, data were gathered on the family history of $\mathrm{CKDu}$, the daily water source for the previous five years, history of snake bites, and the incidence of malaria, frequent use of indigenous medicine, alcohol intake, smoking, and betel chewing. Conditional logistic regression models were employed to calculate odds ratios and 95 percent confidence intervals for each risk factor using SAS statistical software.

\section{Data Analysis}

The output of both univariate and multivariate test results will be considered. The output of the univariate analysis shows preliminary awareness about factors that influenced the disease but multiple logistic regression analysis was the more precise analysis since there is a single dichotomous outcome and more than one independent variable. One of the reasons for using a linear logistic model in this analysis of data is that the coefficients of exploratory variables in the model can be interpreted as logarithms of odds ratios. This means that estimates of the relative risk of the disease and corresponding standard errors can be easily obtained from fitted models. The Chi-Square statistic in the proc logistic procedure of SAS output tests whether the parameter estimates equals zero. From the output, the P-value of the test could be used to reject or accept the null hypothesis ( $\mathrm{HO}$ ) and conclude that each factor is significantly related to disease occurrence. Fitting a model will entail evaluating the unknown parameters in the model. The most essential strategies in fitting models are the maximum likelihood approach and the least square approach. When fitting linear regression models, the least-squares approach is commonly used. However, the maximum likelihood technique, which is created, is the most often used general approach of estimating.

As aforementioned, the study design was matched, the model parameters were analyzed using multivariate analysis and were calculated using conditional maximum likelihood in multivariate analysis. The odds ratios and 95 percent confidence intervals were calculated using univariate and multivariate analytic estimates. At defined levels of relevant individual variables, the likelihood of disease occurrence was identified and utilized as an indicator. The odds ratio is a ratio of "odds" that was derived as a measure of each factor's relative risk. The fundamental goal of risk estimation was to be able to compare disease risks at different levels of exposure variables and thereby assess the associations between the disease and exposure factor. Each conceivable risk factor is divided into two categories: "exposed" and "unexposed." This is a measure of how likely someone who is exposed to a potential risk factor is to get the disease compared to someone who is not exposed. The odds ratio was used to assess the relationship between disease occurrence and exposure factors. For linear logistic modeling, SAS (Statistical Analysis System) (version 8) was utilized as the computer software system. To fit linear logistic models to binary data, the method of proc logistic was employed. This approach contains a variety of sequential processes for model selection and enables a wide variety of model checking diagnoses to be acquired directly. Minitab was used to produce box plot diagrams because of its graphic capabilities.

\section{Results}

Data from the case-control study could be evaluated using linear logistic regression modelling in univariate analysis. This modelling technique's strength, like that of linear regression, comes in its capacity to model several variables simultaneously. Univariate linear logistic model analysis shows that $88 \%$ of cases and $78 \%$ of the control group are involved in agricultural activities in the study area and the status of protective measures against agrochemicals, cultivated land area, and hiring labour for agricultural practices could be considered as occupation-related risk factors. According to the involvement in agricultural practices 


\section{Epidemiology International Journal}

(OR $=2.12,95 \% \mathrm{CI} ; 1.33-3.38)$, low preventive measures against agrochemicals ( $\mathrm{OR}=8.4,95 \% \mathrm{CI}$; 4.49-15.59), agricultural activities without labour exchange $(\mathrm{OR}=2.77$, 95\% CI; 1.85-4.14), high cultivated land area (more than 2 ha) (OR $=2.32,95 \% \mathrm{CI}$; 1.52-3.53), were identified as significant occupation-related risk factors for the disease occurrence $(\mathrm{P}<0.01)$.

The odds ratio of agricultural workers is higher in both univariate and multivariate analysis. Thus, inferring that water and its attributes may play a role in the development of the disease. When considering the above-mentioned odds ratio in agricultural activities-related risk factors, the magnitude of relative risk is highest in low protective levels against agrochemicals. Table 1 show that $92 \%$ of the cases and $58 \%$ of the controls have a low level of protective measures. Pesticides, weedicides, and some fertilizers (Urea) were widely used. However, there were no significant differences in the kind of agrochemicals utilized between cases and controls.

\begin{tabular}{|c|c|c|c|c|c|}
\hline Parameter & df & Estimate & Standard error & Wald Chi-Square & P value \\
\hline Family history of CKDu & 1 & 1.0329 & 0.2576 & 16.0831 & $<.0001$ \\
\hline $\begin{array}{c}\text { Involvement of agricultural activities }>\text { 2 hectares of } \\
\text { land extent }\end{array}$ & 1 & 1.2281 & 0.279 & 19.3691 & $<.0001$ \\
\hline $\begin{array}{c}\text { Cultivating land without hiring labor } \\
\text { Protective status against agrochemicals }\end{array}$ & 1 & 1.4777 & 0.2757 & 28.7276 & $<.0001$ \\
\hline Smoking & 1 & 1.0823 & 0.3395 & 10.1631 & 0.0014 \\
\hline History of Snake bites & 1 & 0.4712 & 0.2757 & 2.9212 & 0.0874 \\
\hline Drinking water source & 1 & 0.7176 & 0.3679 & 3.8048 & 0.0511 \\
\hline
\end{tabular}

Table 1: Maximum Likelihood Estimation Analysis.

In addition to the occupation related risk factors, a history of smoking (OR=1.92, 95\%, CI; 1.37-2.71) $(\mathrm{P}<0.01)$, history of alcohol consumption (OR=1.63, 95\% CI;1.162.31) $(\mathrm{P}<0.01)$, and history of snake bites $(\mathrm{OR}=1.44,95 \%$ CI; 0.96-2.159) $(\mathrm{P}<0.10)$ were identified as other possible risk factors when compared with healthy individuals. The drinking water source of $92 \%$ of cases was from shallow wells $(\mathrm{OR}=1.62,95 \% \mathrm{CI} ; 0.92-2.85)(\mathrm{P}<0.10)$ and there is evidence to suggest that water quality plays a role in the development of the disease which could be identified as a contributory risk factor. Other drinking water sources are tube wells, natural springs, and reservoirs, etc. Genetic predisposition also plays a major role in CKDu and having a family history of renal dysfunction due to $\mathrm{CKDu}(\mathrm{OR}=2.66$, 95\% CI; 1.79-3.96) $(\mathrm{P}<0.01)$ is also a significant risk factor. Pedigrees were drawn for three generations to identify the likely inheritance of the disease considering the precision of the available data. Thirty-six percent (36\%) of the CKDu patients had a family history of renal dysfunction suggesting a genetic aetiology of the disease. However, this could also be due to the same geo-environmental exposure such as drinking from the same water sources. There was no indication of Mendelian inheritance in the pedigrees. History of malaria (OR=1.26, 95\% CI; 0.89-1.774), use of Ayurvedic or indigenous medicine (OR=1.194, 95\% CI; 0.79-1.81) and betel chewing $(\mathrm{OR}=0.789,95 \% \mathrm{CI}$; 0.56-1.12) were not significant risk factors $(\mathrm{P}<0.10)$ when compared to cases and controls in the study.
The univariate analysis data from the case-control study was analyzed using linear logistic regression modelling. As in the case of linear regression, the strength of the modelling technique lies in its ability to model many variables simultaneously. This will be referred to as a "multivariate case". Central to the concentration of multiple logistic models will be an estimation of the coefficients in the model and testing for the significance. Since the design was a matched case-control design, the multivariate analysis referred to conditional logistic regression techniques which were used to investigate the relationship between the outcome of being a case or control and a set of prognostic factors. The dependent variable of interest, the presence of the CKD, was constructed as the above independent variable in a conditional logistic regression model. Table 2 shows the "Analysis of Maximum Likelihood Estimates" which contains the results of the Wald test for individual parameters and lists the parameter estimates with their standard errors. The conditional logistic regression model will not report an intercept in the output.

Conditional logistic regression model (Table 2) indicated that participants who were partaking in agricultural activities that were over 2 hectares of land (OR=3.415, 95\% CI; 1.976-5.900), low preventive measures against exposure to agrochemicals $(\mathrm{OR}=1.966,95 \% \mathrm{CI} ; 1.132-3.414)$ and low level of labour exchange $(\mathrm{OR}=4.383,95 \% \mathrm{CI}$; 2.553-7.524) are significant risk factors for $\mathrm{CKDu}(\mathrm{P}<0.05)$. Smoking $(\mathrm{OR}=2.951,95 \% \mathrm{CI} ; 1.517-5.741)$ and having a family history 


\section{Epidemiology International Journal}

of $\mathrm{CKDu}(\mathrm{OR}=2.809,95 \% \mathrm{CI} ; 1.696-4.654)$, and consuming water from shallow wells (OR=2.050, 95\% CI; 0.997-4.215) were identified as contributory factors $(\mathrm{P}<0.05)$. History of snake bites also had a significant association $(\mathrm{OR}=1.602$,
95\% CI; 0.933-2.750) ( $\mathrm{P}<0.1)$ whereas alcohol consumption, history of malaria, betel chewing, and regular use of indigenous medicine did not show a significant association to $\mathrm{CKDu}$ when compared with the control group.

\begin{tabular}{|c|c|c|c|c|c|c|c|c|}
\hline \multirow{2}{*}{ Risk factor (variable) } & \multirow[b]{2}{*}{ Level } & \multicolumn{2}{|c|}{ Case } & \multicolumn{2}{|c|}{ Control } & \multirow{2}{*}{$\begin{array}{l}\text { Odds } \\
\text { ratio }\end{array}$} & \multirow{2}{*}{$P$ value } & \multirow{2}{*}{$\begin{array}{l}95 \% \text { CI Lower } \\
\text { limit- upper } \\
\text { limit }\end{array}$} \\
\hline & & $\mathbf{n}$ & $(\%)$ & $\mathbf{n}$ & $(\%)$ & & & \\
\hline \multirow{2}{*}{$\begin{array}{c}\text { Involvement of agricultural } \\
\text { activities }>2 \text { hectares of land } \\
\text { extent }\end{array}$} & Yes & 194 & $71 \%$ & 136 & $50 \%$ & \multirow[b]{2}{*}{3.415} & \multirow[b]{2}{*}{$<.0001$} & \multirow[b]{2}{*}{$1.976-5.900$} \\
\hline & No & 80 & $29 \%$ & 138 & $50 \%$ & & & \\
\hline \multirow{2}{*}{$\begin{array}{l}\text { Cultivating land without hiring } \\
\text { labour }\end{array}$} & Yes & 114 & $42 \%$ & 52 & $19 \%$ & \multirow{2}{*}{4.383} & \multirow{2}{*}{$<.0001$} & \multirow{2}{*}{$2.553-7.524$} \\
\hline & No & 160 & $58 \%$ & 222 & $81 \%$ & & & \\
\hline \multirow{2}{*}{$\begin{array}{l}\text { Protective status against } \\
\text { agrochemicals }\end{array}$} & High exposure & 162 & $59 \%$ & 102 & $37 \%$ & \multirow{2}{*}{1.966} & \multirow{2}{*}{0.0164} & \multirow{2}{*}{$1.132-3.414$} \\
\hline & Low exposure & 112 & $41 \%$ & 172 & $63 \%$ & & & \\
\hline \multirow{2}{*}{ Smoking } & Yes & 146 & $53 \%$ & 102 & $37 \%$ & \multirow{2}{*}{2.952} & \multirow{2}{*}{0.0014} & \multirow{2}{*}{$1.517-5.741$} \\
\hline & No & 128 & $47 \%$ & 172 & $63 \%$ & & & \\
\hline \multirow{2}{*}{ Family history of CKDu } & Yes & 99 & $36 \%$ & 48 & $18 \%$ & \multirow{2}{*}{2.809} & \multirow{2}{*}{$<0.0001$} & \multirow{2}{*}{$1.696-4.654$} \\
\hline & No & 175 & $64 \%$ & 226 & $82 \%$ & & & \\
\hline \multirow{2}{*}{ Drinking water source } & Shallow wells & 252 & $92 \%$ & 240 & $88 \%$ & \multirow{2}{*}{2.05} & \multirow{2}{*}{0.0501} & \multirow{2}{*}{$0.997-4.215$} \\
\hline & Other & 22 & $8 \%$ & 34 & $12 \%$ & & & \\
\hline \multirow{2}{*}{ History of Snake bites } & Yes & 69 & $25 \%$ & 52 & $19 \%$ & \multirow{2}{*}{1.602} & \multirow{2}{*}{0.0874} & \multirow{2}{*}{$0.933-2.750$} \\
\hline & No & 205 & $75 \%$ & 222 & $81 \%$ & & & \\
\hline
\end{tabular}

Table 2: Odds ratios of agricultural and lifestyle related risk factors in conditional logistic regression.

Box plot diagram Figure 1 shows the dispersion and central tendency of risk probability (risk P) of the disease occurrence in the diseased and non-diseased sample of the study. The case population shows that the high risk and the dispersion are relatively low compared to the control. The risk probability could be used as an index of the disease diagnosis.

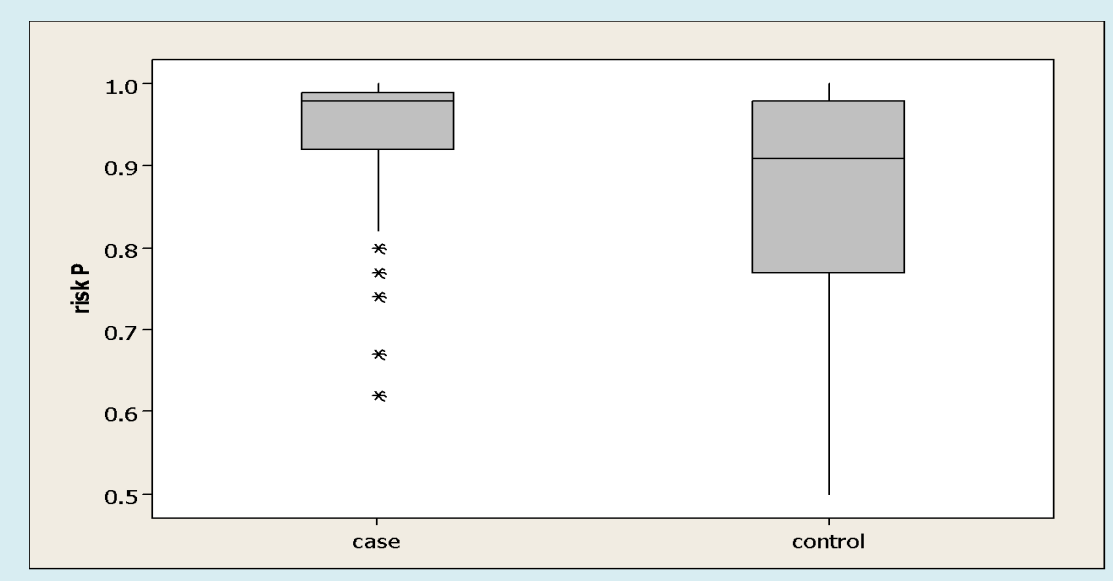

Figure 1: Box plot diagram of risk probabilities of the disease occurrence in case and control. 


\section{Epidemiology International Journal}

\section{Discussion}

CKDu in Sri Lanka is distributed mainly in three provinces of the country [11]. All three provinces are collectively described as North Central Region (NCR). Since $\mathrm{CKDu}$ continues to afflict low-income farming communities, this study mainly focused on agricultural and lifestylerelated variables as predicted risk factors for disease onset and progression. The study elucidated that the majority of agricultural-related activities were found as determinants or predictors of CKDu prevalence in Sri Lanka. The NCR is the country's driest zone, with extremely high mean temperatures compared to other locations. The majority of the farmers toiled in direct sunshine in open farming lands. The increased incidence of $\mathrm{CKDu}$ reported in this research with intensive agricultural activity is comparable to what found in Nicaragua. Cultivating land area greater than 2 hectares and low labour hiring could possibly result in chronic dehydration and electrolyte loss due to excessive sweating. Heat stress can be exacerbated by factors such as poor water intake, a lack of rest periods, improper education and training, wearing clothes that raise body temperature or reduce sweat evaporation, low wages, and a lack of adequate regulation.

Several studies have hypothesized that occupational heat stress cause's chronic dehydration, which impairs kidney function in CKDu [12]. Strenuous occupational labour in hot conditions has been widely recorded, with dehydration being a typical occurrence among these workers $[13,14]$. Previous studies have also observed a decrease in eGFR and serum creatinine at the start and end of the harvesting season, as well as an increase in acute renal injury biomarkers towards the end of the harvesting season $[14,15]$. These studies show that repeated dehydration and occupational heat stress may be linked to the development of CKDu. In the first and second International Research Workshops on CKDu, participants agreed that recurrent bouts of dehydration during hard work in hot conditions, which led to electrolyte loss and Acute Kidney Injury (AKI) [16].

The case opposing heat-stress nephropathy is made by Herath HMNJ, et al. [17]. The study argues that the disease is observed in persons not exposed to heat stress in the afflicted areas and that there is insufficient evidence that it is the main cause of a significant worldwide CKDu outbreak. Similarly, another study found that the overall temporal trends and death patterns for CKD in Central America indicate that the heat/dehydration theory is insufficient to completely explain the outbreak [18]. In El Salvador, came to similar results on the geographical distribution of CKDu. Given that CKDu seems to be a multifactorial disease, heat stress may play a contributory role in exacerbating the causative factor [18]. Social and economic variables such as severe poverty are also risk factors for $\mathrm{CKDu}$ which forces employees to labour in extreme and severe conditions and increase the risk of CKDu $[14,19]$. Agricultural fieldworkers in Nicaragua were shown to have a higher risk of renal disease than non-fieldworkers, which was supported by several studies $[14,15,20]$.

Low protective status had a significant contribution to the disease than the high protected farmers. Information on the frequency of using agrochemicals on their farmlands and concentrations used were inadequately identified in this study as the farmers had poor knowledge in the safe use of the agrochemicals. Pesticide usage has also been high and mostly uncontrolled in Sri Lanka since the green revolution. Furthermore, exposure to hazardous agrochemicals (pesticides and fertilizers) remains a major hypothesis for CKDu in Sri Lanka [21,22]. Heavy metal contamination of commercial pesticide and fertilizer compositions has been established in Sri Lanka [7,23]. In a study, Jayasinghe S [24] went so far as to argue that CKDu in Sri Lanka should be considered to be renamed "chronic agrochemical nephropathy" because of the accumulating evidence linking it to chemical compounds used in agriculture [24].

In Sri Lanka, the NCR has a great number of man-made reservoirs, and the surrounding area is heavily irrigated [11]. People in these locations rely on shallow wells for their water use. As the average depth of a shallow well in these locations is around 20 feet, the likelihood of pesticide contamination from agricultural fields is a risk and concern. Research undertaken in CKDu epidemic regions shows that glyphosate applications were linked to a significantly higher risk of $\mathrm{CKDu}$ among male farmers and laborers [25]. Glyphosate is a nephrotoxic herbicide that is widely used, especially in rice fields in Sri Lanka. Glyphosate, a metal-chelating agent, creates glyphosate-metal complexes when exposed to hard water, and that drinking such water might cause kidney injury $[25,26]$. The onset of the outbreak in Sri Lanka correlates, according to, with the introduction and then the subsequent widespread use of this herbicide in Sri Lanka. As a result, glyphosate can now be regarded as a possible risk factor for CKDu in Sri Lanka. Further studies are required to understand the complexity of several herbicides and their ill effects on farmers.

Snake envenomation is another risk factor found in this study for CKDu. It is a prevalent cause of AKI in tropical nations, affecting primarily young people involved in agricultural occupations [27]. According to Herath HMNJ, et al. [17], 37 percent of individuals who develop AKI after envenomation develop CKD within a year [17]. However, the patients in his study were much older and the majority of them had comorbidities such as diabetes complications and hypertension, both of which are independent risk factors for CKD. According to Waikhom R, et al. [28], 41 percent of 


\section{Epidemiology International Journal}

individuals who suffer envenomation develop long-term renal problems [28]. Furthermore, it is also important to look into other infections and toxins which may act as a risk factor. For instance, Leptospirosis is a widespread zoonotic disease and an asymptomatic illness that is primarily transmitted to humans through water or soil that has been contaminated by the urine of infected animals. Agricultural workers may come into contact with Leptospira bacteria when cultivating and harvesting and develop AKI during severe infections [16]. Although there is no significant evidence that acute Leptospira infections will cause $\mathrm{CKDu}$, it might be a factor that renders patients more vulnerable [29].

According to genetic research, the incidence and the risk of developing conventional CKD may vary by ethnicity, indicating that genetics may play a role in the development of CKDu. A study looked at biomarkers of kidney damage such as the ACR, NAG, NGAL, or IL-18 in 200 nonworking Nicaraguan teenagers. It was found that participants living in areas of greater comparative CKDu death rates have elevated renal biomarker levels [30]. The familial occurrence of the disease with no indication of clear Mendelian inheritance could be due to exposure to the aetiological agent rather than the direct genetic/ inherited background for the disease. However, the history of the patients was limited to three generations as reliable information was not available regarding their parents, grandparents, and relations. Lifestyle-related determinants were also considered in this study. The association of the CKDu with smoking indicates the possibility of the added effect of the toxins and metabolites from these sources, whereas alcohol consumption, history of malaria, betel chewing, and regular use of indigenous medicine didn't show a significant association.

\section{Further Studies and Recommendations}

Multiyear longitudinal studies are required in order to rule out CKD comorbidities. It will help better understand the relationship between the external environmental exposures (e.g., environmental contaminants) versus occupational, lifestyle, and behavioral contributions (e.g. dehydration and heat stress). Funding is also required for preventative studies to identify kidney diseases at the early stages where treatment will be successful. Funding should also be allocated for public health measures that address the risk factors. These include providing a pure water source that is free of chemical or biological contaminants. Deep groundwater, spring water, or bottled water is healthier alternatives. Education and awareness programs on safe agricultural work practices which explain facts like the importance of avoiding heat, starting work early to prevent direct sunlight, taking breaks and rest and adequate hydration should be administered by the government. For instance, OSHA offers agriculture-specific regulations for farmers. It provides information on alternatives to common agricultural hazards and resources like publications to assist employers and workers in creating and maintaining safe and healthy work environments. Provide education and training for the agricultural workers on the safe use of agrochemicals which includes wearing masks, gloves, long sleeve clothes, etc. If workers have a family history of $\mathrm{CKDu}$, they should be educated on environmental risk factors of CKDu to minimize exposure and thereby reduce the chances of getting affiliated with the disease. There is a need to take quick precautionary measures since the epidemic is caused by a combination of factors which includes heat and exposure to harmful toxins. Clinicians should notify occupational safety and public health authorities when they see clusters of patients with chronic renal impairments to support workplace investigations. Given the disease's high mortality and morbidity, attempts to determine the cause(s), deter possible occurrences, as well as provide healthcare for those who have been impacted must be a global priority.

\section{Conclusion}

Certain agricultural practices are associated with a high risk of developing $\mathrm{CKDu}$, according to both univariate and multivariate analyses. As identifying the etiological agent is likely to take longer, limiting exposure to potential risk factors may help manage the incidence of the disease. Toxic chemicals used in agricultural operations, such as pesticides, weedicides, and certain fertilizers, were shown to be related to disease incidence in the majority of epidemiological studies conducted to discover risk factors for CKDu. According to this study, farmers with a low protective level against such agrochemicals contribute significantly more to disease incidence than those with a high protective level. The calculated risk probability might be used to predict the incidence of the disease. The cause(s) is unclear; however, none of the environmental and occupational exposures linked to past nephropathy epidemics have been identified as sole risk factors in the current epidemics. As a result, novel or multifactorial risks must be taken into account. Examining the similarities as well as the differences in CKDu occurring in various geographic locations throughout the world might help researchers figure out what's causing this extreme form of kidney disease.

\section{Acknowledgement}

The authors also acknowledge the assistance received from the scholars whose articles are cited and included in references of this manuscript. The authors are also grateful to authors/editors/publishers of the articles, journals and books from where the literature for this article has been reviewed and discussed. 


\section{References}

1. Nahas AME, Bello AK (2005) Chronic kidney disease: the global challenge. Lancet 365(9456): 331-340.

2. Wijewickrama ES, Weerasinghe D, Sumathipala PS, Horadagoda C, Lanarolle RD, et al. (2011) Epidemiology of chronic kidney disease in a Sri Lankan population: experience of a tertiary care center. Saudi J Kidney Dis Transpl 22(6): 1289-1293.

3. Wanigasuriya KP, John RJP, Wickremasinghe R, Hittarage A (2007) Chronic renal failure in North Central Province of Sri Lanka: an environmental exposure induced disease. Trans R Soc Trop Med Hyg 101(10): 1013-1017.

4. Athuruliya NTC, Abeysekara DTDJ, Amarasinghe PH, Kumarasiri R, Bandara P, et al. (2011) Uncertain etiology of proteinuric- chronic kidney disease in rural Sri Lanka. Kidney Int 80(11): 1212-1221.

5. Chandrajith R, Nanayakkara S, Itai K, Aturaliya TN, Dissanayake CB, et al. (2010) Chronic kidney diseases of uncertain etiology (CKDue) in Sri Lanka: geographic distribution and environmental implications. Environ Geochem Health 33(3): 267-278.

6. Steele P, Marawila D, Gunawardena A, Dharmaratne D (2006) Poverty and Social Impact Analysis (PSIA) of Sri Lanka's Land Reforms. Institute of Policy Studies of Sri Lanka.

7. Bandara JMRS, Senevirathna DMAN, Dasanayake DMRSB, Herath V, Bandara JMRP, et al. (2008) Chronic Renal Failure among farm families in cascade irrigation system in Sri Lanka associated with elevated dietary cadmium levels in rice and freshwater fish (Tilapia). Environ Geochem Health 30(5): 465-478.

8. John RJP, Wanigasuriya JKP, Wickremasinghe AR, Dissanayake WP, Hittarage A (2006) Exposure to acetylcholinesterase-inhibiting pesticides and chronic renal failure. Ceylon Med J 51(1): 42-43.

9. Wanigasuriya KP, Peiris $\mathrm{H}$, Ileperuma N, John RJP, Wicramasinghe R (2008) Could ochratoxin A in food commodities be the cause of chronic kidney disease in Sri Lanka?. Transactions of the Royal Society of Tropical Medicine and Hygiene 102(7): 726-728.

10. Wijetunge $\mathrm{S}$, Ratnatunge $\mathrm{N}$, Ratnatunge $\mathrm{C}$, Abeysekara DTDJ, Wazil AWM, et al. (2012) Endemic kidney disease of unknown aetiology of Sri Lanka: Histopathological changes in kidneys of asymptomatic patients. Sri Lanka Medical Association, research symposium on CKDu.

\section{Epidemiology International Journal}

11. Jayasekara JM, Dissanayake DM, Adhikari SB, Bandara P (2013) Geographical distribution of chronic kidney disease of unknown origin in North Central Region of Sri Lanka. Ceylon Med J 58(1): 6-10.

12. Rotter CR, Wesseling C, Johnson RJ (2014) CKD of unknown origin in Central America: The case for a Mesoamerican nephropathy. Am J of Kidney Dis 63(3): 506-520.

13. Trabanino RG, Jarquin E, Wesseling C, Johnson RJ, Quiroz MG, et al. (2015) Heat stress, dehydration, and kidney function in sugarcane cutters in El Salvador-A cross-shift study of workers at risk of Mesoamerican nephropathy. Environ Res 142: 746-755.

14. Wesseling C, Aragon A, Gonzalez M, Weiss I, Glaser J, et al. (2016) Kidney function in sugarcane cutters in Nicaragua-A longitudinal study of workers at risk of Mesoamerican nephropathy. Environ Res 147: 125-132.

15. Laws RL, Brooks DR, Amador JJ, Weiner DE, Kaufman JS, et al. (2015) Changes in kidney function among Nicaraguan sugarcane workers. Int J Occup Environ Health 21(3): 241-250.

16. Chicas R, Mix J, Mac V, Flocks J, Dickman NE, et al. (2019) Chronic Kidney Disease Among Workers: A Review of the Literature. Workplace Health Saf 67(9): 481-490.

17. Herath HMNJ, Wazil AWM, Abeysekara DTDJ, Jeewani NDC, Weerakoon KGAD, et al. (2012) Chronic kidney disease in snake envenomed patients with acute kidney injury in Sri Lanka: a descriptive study. Postgrad Med J 88(1037): 138-142.

18. Van Dervort DR, Lopez DL, Orantes CM, Rodriguez DS (2014) Spatial Distribution of Unspecified Chronic Kidney Disease in El Salvador by Crop Area Cultivated and Ambient Temperature. Medicc Rev 16(2): 31-38.

19. Bodin T, Trabanino RG, Weiss I, Jarquin E, Glaser J, et al. (2016) Intervention to reduce heat stress and improve efficiency among sugarcane workers in El Salvador: Phase 1. Occup Environ Med 73(6): 409-416.

20. Torres C, Aragon A, Gonzalez M, Lopez I, Jakobsson K, et al. (2010) Decreased kidney function of unknown cause in Nicaragua: A community-based survey. Am J Kidney Dis 55(3): 485-496.

21. WHO (2016) International expert consultation on chronic kidney disease of unknown etiology.

22. Jayatilake N, Mendis S, Maheepala P, Mehta FR (2013) Chronic kidney disease of uncertain aetiology: prevalence and causative factors in a developing country. 


\section{Epidemiology International Journal}

BMC Nephrol 14: 180.

23. Weeraratna C (2013) Fertilizer use in Sri Lanka with special reference to Chronic Kidney Disease of unidentified etiology (CKDu). Symposium on "Chronic Kidney Disease of uncertain origin (CKDu): a scientific basis for future action". Colombo: Galadari Hotel.

24. Jayasinghe S (2014) Chronic kidney disease of unknown etiology should be renamed chronic agrochemical nephropathy. MEDICC Rev 16(2): 72-74.

25. Jayasumana C, Paranagama P, Agampodi S, Wijewardane C, Gunatilake S, et al. (2015) Drinking well water and occupational exposure to herbicides is associated with chronic kidney disease, in Padavi-Sripura, Sri Lanka. Environ Health 14: 6.

26. Jayasumana M, Paranagama $P$, Amarasinghe $M$, Fonseka $S$ (2013) Arsenic, lead and cadmium in technical organic pesticide compositions and in fertilizers available in the Sri Lankan market. Addendum on pesticides as a possible causal factor of MeN. Mesoamerican nephropathy: report from the first international research workshop on MeN. Heredia. SALTRA, IRET-UNA, pp: 239-240.

27. Priyamvada PS, Jaswanth C, Zachariah B, Haridasan S, Parameswaran S, et al. (2020) Prognosis and longterm outcomes of acute kidney injury due to snake envenomation. Clinical Kidney Journal 13(4): 564-570.

28. Waikhom R, Sircar D, Patil K, Bennikal M, Gupta SD (2012) Long-term renal outcome of snake bite and acute kidney injury: a single-center experience. Ren Fail 34(3): 271-274.

29. Yang CW (2018) Leptospirosis renal disease: Emerging culprit of chronic kidney disease unknown aetiology. Nephron 138(2): 129-136.

30. Rubio OR, Amador JJ, Kaufman JS, Weiner DE, Parikh $\mathrm{CR}$, et al. (2016) Urine biomarkers of kidney injury among adolescents in Nicaragua, a region affected by an epidemic of chronic kidney disease of unknown aetiology. Nephrol Dial Transplant 31(3): 424-432. 